\title{
Combined Heat and Power's Potential to meet New York City's Sustainability \\ Goals
}

\author{
Bianca Howard ${ }^{1 *}$, Alexis Saba ${ }^{2}$, Michael Gerrard ${ }^{2}$, Vijay Modi ${ }^{1}$ \\ Department of Mechanical Engineering, Columbia University ${ }^{1}$ \\ Center for Climate Change Law, Columbia University ${ }^{2}$
}

\begin{abstract}
Combined Heat and Power (CHP) has been proven as a mature technology that can benefit both building owners and utility operators. As the economic and environmental benefits of CHP in urban centers gain recognition, regulations and policies have evolved to encourage their deployment. However, the question remains whether these policies are sufficient in helping to achieve the larger sustainability goals, such as the New York City-specific goal of incorporating $800 \mathrm{MW}$ of distributed generation. In this paper, the current regulatory and policy environment for CHP is discussed. Then, an engineering analysis estimating the potential for CHP in NYC at the individual building and microgrid scale, considered a city block, is performed. This analysis indicates that over 800 MW of individual building CHP systems would qualify for the current incentives but many systems would need to undergo more cumbersome air permitting processes reducing the viable capacity to $360 \mathrm{MW}$. In addition microgrid CHP systems with multiple owners could contribute to meeting the goal even after considering air permits; however, these systems may incorporate many residential customers. The regulatory framework for microgrids with multiple owners and especially residential customers is particularly uncertain therefore additional policies would be needed to facilitate their development.
\end{abstract}

Keywords: Combined Heat and Power, Urban Energy System Planning, Regulatory and Policy Barriers,

\section{Introduction}

Many countries around the world have recognized the need to reduce greenhouse gas emissions to mitigate climate change. The $\mathrm{C} 40$ initiative, which brought together mayors from 58 cities around the world including 10 within the US, is committed to reducing the carbon footprint of the participating cities. New York City is a part of this group and has discussed their goals to create a more sustainable urban environment in the document, PlaNYC (NYC, 2007). Specifically, the city has expressed a goal to reduce greenhouse gas emissions $30 \%$ by 2030 . Government officials have recognized that distributed generation can play a role in achieving these reductions and have included a target of 800 MW of distributed generation (DG) development, which includes combined heat and power (CHP) systems.

\footnotetext{
* Corresponding Author, Email: bnh2111@columbia.edu, Address: Mudd 220, 500 W 120 $0^{\text {th }}$

Street, New York, NY, 10027 Phone: 212-854-7306
} 
CHP systems have been used as a technology to reduce energy consumption and greenhouse gas emissions due to their high relative efficiencies (EPA, 2008). Typically, electricity and thermal energy are generated by separate sources: centralized power plants and local boilers. While boilers can be quite efficient at converting fossil fuels into thermal energy, power generation equipment converts fossil fuel into electricity at a lower efficiency, ranging from 30 to $50 \%$. When heat that is otherwise rejected during power generation is used to meet a thermal load, CHP systems can increase the utilization of fossil energy sources from these low efficiency values to as high as $60 \%$ to $80 \%$ efficiency. CHP systems can also contribute to grid reliability and defer costly transmission and distribution system upgrades by generating electricity locally.

Initial adoption of CHP was by utilities and industrial companies. Over the last few decades, CHP systems were also deployed in large college campuses and hospitals, for energy efficiency and economic reasons. More recently in New York State and New York City, CHP systems have also seen adoption at the individual building level.

In attempting to deploy CHP systems, many developers (whether at campus or individual building scale) have come across regulatory barriers that hinder increased penetration of CHP at these smaller scales. Some of the barriers included lack of financial incentives, overly burdensome utility and regulatory requirements, as well as designing to meet environmental permitting requirements. While there have been many reports on the barriers to implementing additional CHP capacity (Chittum and Kaufman, 2011; Bourgeois et al., 2003; Hammer and Mitchell, 2007; Lemar, 2001; Mueller, 2006), over time, policies and regulations have been introduced to reduce those barriers. Significant progress has been made to facilitate additional CHP but are these measures enough to allow for the magnitude of development outlined by the City for a sustainable future?

An additional consideration is the recent interest in the development of microgrids within the existing electricity infrastructure. A microgrid, for the purposes of this paper, is defined as a local distributed generation resource(s) physically connected to and serving the electric and thermal loads of multiple users. While microgrids have been installed on large campuses, these installations have typically been limited to single-owner properties. New ideas consider utilizing microgrids to connect buildings owned by multiple entities, either within a block or across streets. The regulation of microgrids, specifically regarding the ownership structure and physical placement of the systems, is largely undeveloped (Hyams, 2010)-leaving uncertainty in the deployment process of microgrids.

While a full economic feasibility analysis of combined heat and power would incorporate many aspects such as future commodity prices and electricity infrastructure, the current analysis seeks to estimate technical potential for CHP at both the building and microgrid scales, and to evaluate which systems would be eligible for the current regulatory and policy measures for CHP. This will illuminate whether the current measures will ease the development of enough future CHP systems to meet the DG goal of $800 \mathrm{MW}$ and if not which measures 
could be expanded to facilitate more development. The remainder of this paper will discuss the previously identified barriers to CHP development in the United States, the current measures to mitigate these barriers, estimate the potential for $\mathrm{CHP}$ at the building and microgrid scales in NYC, and then discuss how many of potential systems would be eligible for the current measures in comparison to the city's goal of introducing $800 \mathrm{MW}$ of distributed generation.

\section{Identified Barriers to CHP Development}

Multiple studies have identified barriers to CHP development in the United States, specifically New York State and New York City. In this section, some of the commonly cited issues with CHP development will be reviewed.

\subsection{Interconnection to the Local Utility}

Connection to the local utility for electrical services with consideration to availability, cost, and processing time of the request has been cited as a barrier to CHP development in several studies. For a CHP system to connect to the local utility, the proposed interconnection must undergo a process designed to assess the impacts of the CHP system on the existing grid. This process can be complex and the duration is variable. The time delays associated with the process can add extra project costs and make the project unfeasible. Also, during this assessment, the developer may be responsible for fees associated with the study as well as cost for any supplemental equipment (Bourgeois et al., 2003; Hammer and Mitchell, 2007). In addition to the study for interconnection, there may also be geographical limitations due to fault current limits at various locations in the electrical grid. This means that while the project may be technically feasible from the customer side of the meter, the addition of generation assets on the grid may risk the current electrical infrastructure, which may incur additional costs or prevent the project from moving forward (Hammer and Mitchell, 2007).

As most CHP systems will not provide all of the electricity or heating needs of a building or community, these systems also need to contract standby electricity, gas, and/or steam from the local utility. The structure of these back up and/or stand by tariffs are much different than the standard charges and if not fully accounted for can be very costly. In previous works, the rate structure for which a system is charged for backup electricity has been cited as economically prohibitive (Bourgeois et al., 2003; Hammer and Mitchell, 2007; Mueller, 2006) and systematically unfair.

\subsection{Financing the CHP System}

As the investment in a CHP system requires significant capital costs, the financing of the system is very important for development. While CHP systems generally incur larger pay back periods than other energy efficiency measures, even if a facility owner feels that the time is acceptable, the perceived risk by financiers can prevent developers from securing funds for the project. (ACEEE, 2011; Bourgeois et al., 2003).

\subsection{Compliance with Environmental Permitting}


While environmental permits and policies are in place to protect the local residents and environment, compliances with these permits, depending on the size of the system, can add delays and cost to the project. There are different levels of registration and permits required by a CHP system depending on the magnitude of the emissions output. For emissions regulations in New York State, a system can be seen as exempt or require minor facility registration, a State Facility Permit, or a Major Facility Title V Permit. Obtaining a Major Facility permit requires additional time and cost measures which may, depending on the project economics, make a system infeasible (ACEEE 2011; Bourgeois et al. 2003; Hammer and Mitchell 2007). Compliance with the air permits is not a barrier per se, but will limit the amount of CHP that would be feasible in a particular location.

\subsection{Local Codes and Permits}

The installation of a CHP system requires permits and inspections from multiple city agencies: the department of buildings, the fire department of New York, and the department of environmental protection. Many times the local codes and permit requirements penalize CHP as the codes have not been updated to reflect the regular installation of CHP systems (Hammer and Mitchell 2007; Mueller 2006). Because of these irregularities, the time to obtain these permits varies significantly from project to project adding additional cost and risk to implementing a CHP system (ACEEE 2011). For example, Hammer and Mitchell (2007) cite fire codes as being prohibitive as they are not adjusted to account for high-pressure lines needed to feed building level micro-turbine CHP systems.

\subsection{Regulatory treatment of Microgrid CHP Systems}

In a NYSERDA report, Hyams (2010) outlines potential treatment of microgrids by regulatory entities in New York depending on various aspects of the system through review of various regulatory documents and precedents. Being regulated as an electric corporation allows the New York State Public Service Commission (PSC) to determine rates that a facility is able to charge, the quality of service provided, methods of billing implementation, and many other aspects of operations. Because of these many oversights, definition as an electric corporation tends to be avoided. Fortunately, distributed CHP systems would be termed a "qualifying facility," exempt from regulation as an electric or steam corporation. A qualifying facility can distribute thermal and electric power to "related facilities" that are located at or near the generation site, but this definition has primarily been used to justify transmission to single owners. In the event the distribution system is termed a related facility if these systems were to cross the public way (i.e. streets), the developers would be required to petition for a revocable consent permit allowing them to place the desired infrastructure. This petition may need to go through many city agencies, which would add time and complexity to the project. Also the incorporation of residential customers that are not partial owners of the system would most likely be required to follow the statutory consumer protections as established by the Public Service Law. These protections would require similar oversights as an electric corporation. 
The regulatory treatment of microgrids utilizing CHP will depend significantly on the types of customers served, as well as whether or not the system would require distribution and transmission systems to cross the public way.

\section{Measures to Mitigate Barriers to CHP in New York State}

In New York, steps have been made to alleviate some of these barriers, mainly through financial incentives and streamlining of interconnection requirements as described in the next sections.

\subsection{Financial Incentives}

NYSERDA, the New York State Energy Research and Development Association, has developed multiple incentive programs that reduce the upfront capital costs for developers to help facilitate CHP development. Two of its primary CHP programs, the DG/CHP Demonstration Project and the Existing Facilities Program, have recently expired; however, approximately $16 \mathrm{MW}$ of CHP have been deployed with the aid of these incentives. The DG/CHP Demonstration Project was developed to support the permanent installation of CHP systems (Peters and DeSimoine, 2011), while the Existing Facilities Program was designed to reduce summer peak electricity demand (NYSERDA, 2012a). Each of the incentives would cover up to $50 \%$ of the total project costs. The primary requirements for qualification were capability of reducing power consumption from the perspective of the grid during peak demand hours, as well as a minimum annual CHP efficiency of $60 \%$.

In addition to expired programs, NYSERDA is establishing a CHP Acceleration Program that pre-qualifies CHP "modular kits," 1.3 MW or smaller, for \$20 million of NYSERDA incentives available to customers who purchase and install the systems. The approved systems "must be capable of acquiring proper air permits [. . .] and capable of interconnecting to New York State electric utilities," meaning that the systems will be proven to already meet some regulatory and utility requirements (NYSERDA, 2012b). The packaged equipment will improve the comfort of agencies and utilities with CHP and streamline the permitting and approval processes.

\subsection{Streamlined Interconnection Requirements}

In addition to financial solutions, the New York State PSC has implemented streamlined and standard interconnection requirements. Each utility has its own electrical interconnection requirements, although the PSC's Standardized Interconnection Requirements (SIR) covers CHP systems smaller than $2 \mathrm{MW}$, and the New York Independent Systems Operator (NYISO) Standard Large Facility Interconnection Procedures (LFIP) covers systems larger than $20 \mathrm{MW}$ (NYS PSC, 2012). Systems that can follow standardized interconnection procedures are often faster and less cumbersome to design and install because developers know the requirements from the beginning and do not need an individual review by Con Edison, the local utility. Systems $25 \mathrm{~kW}$ and smaller undergo an expedited application procedure. The SIR provides timelines for approvals as well as mandates the creation of a web-based system to allow 
developers to see the progress of the SIR applications. Con Edison has attempted to expedite the process by creating an ombudsperson to facilitate communication between the utility and the local developer. The ombudsperson's role is to serve as a central point of contact once an application is filed with the Customer Project Manager.

\subsection{Clarification of local codes and regulations}

The NYC Development Hub, launched by the City of New York in October 2011, aims to streamline construction projects throughout New York City by allowing permit applicants to submit materials electronically, in one place, and by virtually bringing together six City agencies (including the New York City Department of Buildings, Fire Department, and Department of Environmental Protection, among others) to review the application materials and discuss project plans. The ideal implementation of this system would reduce the time and confusion in abiding by the local codes and regulations.

\section{Continued Barriers to CHP Development}

Even though the previous measures have been implemented, there are still hurdles to CHP development. In a recent review, Gerrard (2013) cites some of the continued barriers to $\mathrm{CHP}$ in New York and provides suggestions for solutions.

The author cites standby tariffs, which can be prohibitively costly, and the lack of financial mechanisms to help manage up front capital costs as continued barriers to CHP development. Gerrard suggests that the PSC provide easier access to information about changes and modification to tariffs, as well as alter the steam tariff to be more amendable to CHP development. To provide additional financial incentives, Gerrard suggests continuation of programs that allow non-profit entities to obtain government subsidies, such as the previous grant in lieu of the investment tax credits and to make the five-year depreciation deductions available to non-profits.

In addition to the financial barriers, deciphering all of the local codes and permitting processes can still be time consuming and cumbersome even with the recent NYC Development Hub. Gerrard suggests creating a handbook that clearly articulates all of the regulatory requirements for CHP installation as well as creating a coordinator position at the city level to help facilitate with communications.

While there are still hurdles to CHP development, the following engineering analysis will assess the technical potential for CHP systems at the building and microgrid scales, and access the systems for their potential to utilize the measures currently in place to help facilitate CHP.

\section{City Wide Engineering Analysis}

The primary goal of this engineering analysis is to assess the potential for CHP throughout New York City at both the building and microgrid scales. There have 
been previous efforts to quantify the potential for CHP across an existing region (Bourgeious et al., 2003; Finney et al., 2012; Lemar 2001), but many of these analyses do not consider the commercial or residential sector and only utilize annual energy demands. The current analysis seeks to determine the potential for microgrids, which aggregate demands amongst many users, so it was important to incorporate multiple sectors and high temporal resolution as different building types utilize energy at different times. The following sections will describe the methodology used to create hourly thermal and electric demand estimates, the operation/sizing strategy for the CHP system, and the estimated potential for CHP across New York City.

\subsection{Estimates of Hourly Energy Demands}

To analyze the potential viability of CHP systems, it was first necessary to obtain an estimate of each building's energy demand. Initially, annual energy demands were determined for each building using the energy intensities developed from previous analyses. Then, the annual values were modeled to hourly profiles utilizing the profiles developed for the U.S. Department of Energy (DOE) commercial reference buildings (US DOE, 2011). The next paragraphs discuss the development of the annual energy intensities as well as the development of the hourly thermal and electric profiles.

Annual building energy intensities (energy per building floor area) were estimated for (1) seven different building types in New York City: residential 1-4 family (Residential 1-4), residential multi-family (Residential Multi), office, store, education, health and warehouse and (2) four end uses: base electric, space heating, space cooling and water heating (Howard et al., 2012). These intensities were applied to the building area of every tax lot in New York City to estimate the annual base electric and space heating energy consumption. These building types represent $91 \%$ of the total building area in New York City, meaning that estimates of energy consumption were not provided for $9 \%$ of the total building area.

Hourly energy intensities were extrapolated using the DOE commercial reference building load profiles. These reference buildings were created to model the behavior of typical commercial buildings. The building energy consumption was estimated for 16 buildings types in 16 different climate regions (US DOE, 2011). These prototypical buildings were intended not to provide information about a specific building but rather to provide an estimation of how a building with particular characteristics would behave on average. The building prototypes were created using the energy modeling software EnergyPlus (Crawley et al., 2001) using inputs from various sources.

The analysis used load profiles from a subset of these buildings to estimate the hourly behavior of New York City buildings based on building type. The intention of using these hourly profiles was not to accurately estimate the hourly energy consumption for every building in New York City, but rather to obtain a general picture of the variation of electricity and space heating energy consumption in time. While the annual energy intensities and therefore annual 
energy consumption figures are representative of New York City, the hourly breakdown is not.

The DOE commercial reference buildings utilized more building types than those used to estimate New York City annual energy intensities. Therefore, only the prototypical buildings that corresponded with the building types used to estimate annual intensities were considered. The annual energy intensity building types and the corresponding DOE commercial reference building types are shown in Table 1. The climate region used for the DOE commercial reference buildings was 4A, whose representative city was Baltimore, Maryland. The 4A region includes New York City within its boundaries. In addition to specifying more building types, the EnergyPlus model provided estimates of additional end uses. The estimated New York City annual end uses and the corresponding end uses from the EnergyPlus model are shown in Table 2. For this analysis, only space heating and base electric loads, which consist of electricity used for lighting, refrigeration, and plug loads (but not cooling), were considered.

The following equation was used to create New York City-specific hourly energy consumption intensities:

$$
e_{h, b, u}^{n y c}=r_{b, e} * e^{d o e} h, b, u
$$

where $e^{n y c} h, b, u$ is the New York City-specific energy consumption intensity for hour, $\mathrm{h}$, building type as in the first column of Table 1, b, and end use as in the first column of Table 2, $\mathrm{u}, r_{b, e}$ is the ratio of the annual New York City energy intensity to the annual intensity from the DOE commercial reference building for building type, $\mathrm{b}$, and end use, $\mathrm{u}$, and $e_{h, b, u}^{d o e}$ is the energy intensity from the DOE commercial reference buildings for hour, $h$, building type as in the second column of Table 1, b, and end use as in Table 2, u.

Table 1. NYC and DOE commercial reference building types.

\begin{tabular}{|l|l|}
\hline Annual NYC Building Types & DOE commercial building types \\
\hline Residential 1-4 Family & Mid-rise Apartment \\
\hline Residential Multi Family & Mid-rise Apartment \\
\hline Office & Small Office, Medium Office, Large Office \\
\hline Store & Stand-Alone Retail \\
\hline Education & Primary School \\
\hline Health & Outpatient Health \\
\hline Warehouse & Warehouse \\
\hline
\end{tabular}

Table 2. NYC and corresponding DOE commercial reference end uses.

\begin{tabular}{|l|l|}
\hline Annual NYC end uses & DOE commercial end uses \\
\hline Base Electric & Electric - Space Cooling \\
\hline Space Heating & Gas + Electric Space Heating \\
\hline
\end{tabular}


The hourly base electric and space heating demand intensities for the residential multi-family and large office buildings $\left(>9,290 \mathrm{~m}^{2}\right)$ are shown in Figure 1. This methodology assumes that the load profiles scale linearly with building size, which may create load profiles with more variation for larger buildings or less variation for smaller buildings. These hourly intensities were then multiplied by the building area for every tax lot in New York City providing hourly estimates of space heating and non-cooling energy demands.

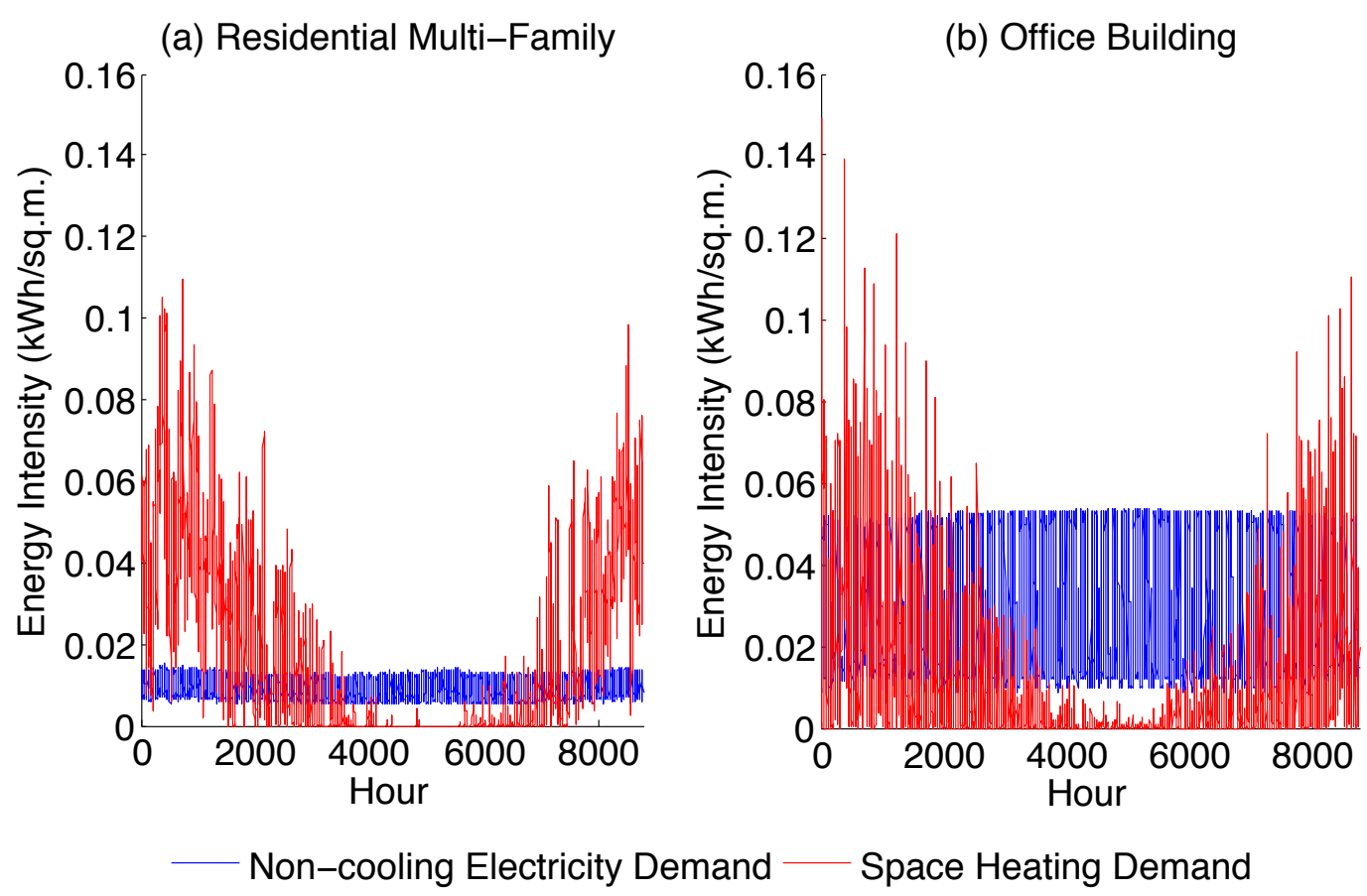

Figure 1. Estimated hourly space heating and non-cooling electric energy demands for (a) a residential Multi-Family building and (b) an office building

In the buildings database used for the analysis, the smallest unit is the tax lot. While most tax lots are only associated with one building, there are instances where a tax lot will contain multiple buildings. For this analysis, tax lot-level opportunities will be discussed as building-level opportunities. Also microgrids were defined utilizing city blocks. While limiting the microgrids to a block may not illuminate every possible microgrid configuration, it does provide an estimate of the magnitude of microgrid opportunities. This also reduces the concern that specific projects would be required to cross the public right of way, which requires additional regulatory attention.

\subsection{Combined Heat and Power Technical Specifications}

There are many different CHP technologies that can be used to satisfy building energy demands. The four main types are steam turbines, internal combustion engines, microturbines, and fuel cells. The U.S. Environmental Protection Agency Catalog of CHP Technologies provides an extensive overview of the various CHP technologies commercially available as well as of their unique specifications. For the current analysis, only internal combustion engines and microturbines were considered as these technologies are typically dispersed in 
sizes for distributed generation, from $30 \mathrm{~kW}$ to $5 \mathrm{MW}$, and are compatible with existing infrastructure, as they can be fuelled by natural gas. Four different technologies were used to represent different capacity ranges. The size ranges and operational efficiencies used are shown in Table 3. The specifications were taken from the GE Jenbacher Technical Specifications (GE, 2011) for the internal combustion engineers and the EPA Catalog of CHP Technologies for the microturbine (EPA, 2008).

Table 3. Representative efficiency characteristics of CHP systems in different capacity ranges.

\begin{tabular}{|c|c|c|c|}
\hline $\begin{array}{c}\text { Electrical } \\
\text { Capacity }\end{array}$ & Prime Mover & $\begin{array}{c}\text { Electric } \\
\text { Efficiency }\end{array}$ & $\begin{array}{c}\text { Thermal } \\
\text { Efficiency }\end{array}$ \\
\hline$<100 \mathrm{~kW}$ & Microturbine & $24.6 \%$ & $46.9 \%$ \\
\hline $100-500 \mathrm{~kW}$ & $\begin{array}{c}\text { Internal Combustion } \\
\text { Engine }\end{array}$ & $35.9 \%$ & $44.8 \%$ \\
\hline $500-1,000 \mathrm{~kW}$ & $\begin{array}{c}\text { Internal Combustion } \\
\text { Engine }\end{array}$ & $38.3 \%$ & $49.2 \%$ \\
\hline$>1 \mathrm{MW}$ & $\begin{array}{c}\text { Internal Combustion } \\
\text { Engine }\end{array}$ & $45.3 \%$ & $41.7 \%$ \\
\hline
\end{tabular}

\subsection{CHP Sizing Methodology}

There are many strategies for how to best operate and size a CHP system such as maximizing revenue, maximizing system efficiency, and minimizing the carbon footprint of the system. Each of the objectives would result in utilization of different types of CHP technologies, numbers of generators used to meet the loads, uses of additional heat recovery systems, as well as operational strategies. For example, when designing a system to maintain maximum plant efficiency, the use of additional systems to recover the most energy from the thermal energy stream may be justified. For an economic analysis where cost is the driver, the additional energy recovered may not justify the cost, and the system components may therefore be less extensive or efficient. Researchers have developed methods to determine the optimal operating strategies and system components for CHP systems depending on the desired outcome and load profiles (time of use energy demands) of the buildings to be sized. These methods typically deploy mixed-integer linear or non-linear programs (Casisi et al., 2009; Hawkes and Leach, 2007, Keirstead et al., 2011; Ren et al., 2010) to determine system size and optimal operational strategies. The operational strategy used to size the CHP systems for the current analysis depends on a less complex methodology than the optimization methods discussed previously, as a more complex analysis is not warranted without more detailed information about the buildings energy demands and physical details.

For the current analysis, four different sizing strategies were considered. Two of the simplest methodologies for operating a CHP system are to meet either the thermal or electric base load. For these methods, the CHP system is operated year round, satisfying the minimum constant electric or thermal demand. This method ensures that the system is sized in such a way to always run at peak load 
and efficiency. For the electric base load method, the CHP system capacity for each building or microgrid scenario was estimated using the following equation,

$$
\operatorname{Cap}_{t}=\min \left(E_{t}\right)
$$

where $\mathrm{Cap}_{t}$ is the maximum electrical capacity of the CHP system in $\mathrm{kW}$ for building or microgrid, t, and $E_{t}$ is the hourly non cooling electricity demand for building or microgrid, $t$. The system capacity for the thermal base load is similar and shown by the following equation,

$$
\operatorname{Cap}_{t}=\min \left(H_{t}\right) / H E_{r}
$$

where $H_{t}$ is the space heating demand for building or microgrid, $\mathrm{t}$, and $H E_{r}$ is the heat to electric ratio for the system in the appropriate size range as discussed in section 4.2.

Two additional sizing methodologies are electric and thermal load following strategies also called electric and thermal demand management (Wang et al., 2011) and electricity- and heat-led (Hawkes and Leach, 2007). These methods size the system to follow either the electric or thermal loads for the majority of the year and require the CHP system to increase or decrease its supply based on demand. Typically CHP systems used to deploy these strategies have high part load efficiencies. The part load efficiency is a measure of how well the system operates when not running at peak load. Internal combustion engines have high part load efficiencies with minimal reduction in efficiency until $60 \%$ of the peak load (ASHRAE, 2008).

The system capacities in the load following strategies utilized a heuristic that first uses the electric demand (or thermal demand for the thermal load following strategy) to estimate the range of possible system sizes. These system sizes were between the maximum and minimum hourly electric (thermal) demand. Then for each possible capacity in $1 \mathrm{~kW}$ intervals, the system efficiency, electric, and thermal output at each hour was calculated.

The CHP systems were allowed to operate at up to $60 \%$ part load depending on the magnitude of the electric (or thermal) demand. If the electric (or thermal) demand was less than $60 \%$ of the capacity of the CHP system, then the system was not operated. The part load efficiencies of the CHP systems were modeled as follows

- the electrical efficiencies were diminished linearly from the maximum efficiency for the current system capacity to a $10 \%$ decrease in efficiency at $60 \%$ part load

- the heat to electric ratio was held constant throughout the system operation.

This part load behavior was shown in performance charts of CHP systems of similar capacity ranges (ASHRAE, 2008). For each potential system capacity, the system with the largest capacity and annual efficiency greater than $60 \%$ was 
chosen as the system size. The annual CHP efficiency for all scenarios was determined using the following equation,

$$
\eta_{c h p}=\frac{\sum P_{b}+\sum Q_{h}}{\sum F_{b}}
$$

where $\eta_{c h p}$ is the annual CHP efficiency, $P_{h}$ is the electric power utilized in hour, h, $Q_{h}$ is the thermal energy utilized in hour, h, and $F_{h}$ is the fuel input to the CHP system in hour, h. For the base load strategies as the system is operating at full load for each hour of the year, the fuel input to the system is the same for each hour; therefore, the efficiency only changes when either electricity or thermal demand can not be utilized in an hour and must be wasted. In the load following strategies, depending on the variation in the loads, both the fuel input and the amount of electricity and thermal energy utilized varies. For all four sizing methods -- electrical base load, thermal base load, electrical load following, and thermal load following -- there will be instances when the systems will need supplementary power for electrical or thermal needs. The supplementary thermal demand was modeled as boilers that provide energy at $85 \%$ efficiency and electricity distributed through the New York City grid.

To determine which of these general sizing and operational strategies to utilize, an analysis was conducted to see how accurate the base loading and load following strategies estimated CHP system capacity. The estimates were calculated for and compared to the current CHP installations that obtained financial incentives from NYSERDA. Any system that received incentives was required to place information about the system characteristics online. These CHP systems were used for the analysis, as it was the only publicly available resource providing information about CHP system size and specific locations. Since these systems were installed to meet specific and different goals leading to different sizing for similar buildings, only the aggregate capacity of systems located in New York City was used to compare the results of the different sizing methods.

Of the four general sizing methodologies, the thermal base load methodology was immediately discarded since, even when considering space heating, space cooling, and domestic hot water as the thermal loads, the CHP systems were dramatically undersized.

Also it is important to note that a minimum $60 \%$ annual efficiency, a requirement for receiving NYSERDA incentives, was imposed for the building and microgrid scales or else a system was not selected. A comparison of the aggregate capacities for the electric base load, electric load following, and thermal load following sizing to the actual systems in the NYSERDA database is shown in Table 4. 
Table 4. Comparison of different sizing methodologies with installed CHP systems with NYSERDA incentives.

\begin{tabular}{|c|c|c|c|c|}
\hline & $\begin{array}{c}\text { NYSERDA } \\
\text { Systems }\end{array}$ & $\begin{array}{c}\text { Electric } \\
\text { Base Load }\end{array}$ & $\begin{array}{c}\text { Electric } \\
\text { Load Follow }\end{array}$ & $\begin{array}{c}\text { Thermal Load } \\
\text { Follow }\end{array}$ \\
\hline $\begin{array}{c}\text { Aggregate } \\
\text { Capacity (kW) }\end{array}$ & 16,410 & 8,880 & 17,266 & 24,066 \\
\hline $\begin{array}{c}\text { Percent } \\
\text { Difference }\end{array}$ & - & $-46 \%$ & $+5 \%$ & $+82 \%$ \\
\hline
\end{tabular}

These analyses were performed utilizing only the estimated space heating and base electric energy demands for each of the buildings. From this analysis, the electric load following methodology provided the closest aggregate estimate. Also, adding the water heating and space cooling demands resulted in even higher differences between the estimates and actual systems. Therefore, the electric load following method considering only space heating as a thermal load was used to estimate the potential for the remaining tax lots and future microgrid scenarios. A minimum size of $30 \mathrm{~kW}$ was maintained to reflect the smallest microturbine technologies. The other sizing methods as well as incorporating the additional loads are not incorrect, but rather alternative sizing methods that will lead to different results (i.e., citywide potentials and individual system capacities). The goal here is to provide an estimate that reflects the sizes of current systems, which is indicative of the current policy and regulatory frameworks.

\subsection{Calculating Emissions Savings}

In addition to estimating the operational efficiency of the CHP systems, the potential emissions benefits were also calculated. The carbon dioxide equivalent $\left(\mathrm{CO}_{2} \mathrm{e}\right)$ was used to estimate the reduction potential. Accounting for emissions benefits is very dependent on local conditions. The method utilized to calculate the potential emissions reductions in this analysis was "the avoided burden approach". This method estimates the reduction potential of a technology by estimating the impact of the energy that would have been supplied if the CHP system was not used. This requires accounting for the emissions from the electricity currently being generated, as well as the emissions and fuel used for the current boilers supplying thermal energy.

The emissions coefficient used to represent greenhouse gas emissions released during electricity production was developed by the 2012 eGrid Assessment (US EPA, 2012). This assessment determines the mix of electricity generation technologies serving a particular region and creates a weighted emissions coefficient based on the amount of electricity generated from each source. In addition to determining the average emissions produced, they have also developed coefficients for base load and non-base load electricity demands. Base load generators (those utilized to supply the minimum electric demand of a region), are typically larger systems with different emissions characteristics than the systems used to supply the time varying peak demands, non-base load. Since in New York City a large portion of base load is supplied by nuclear and hydropower, there is a significant difference between the base load and non-base 
load emissions. A study performed in 1997 estimated the impacts of incorporating $330 \mathrm{MW}$ of combined heat and power into the New York City area in terms of the effects on the electricity generation and emissions (CCAP, 2001). The study found that the CHP system would displace electricity generated by non-base load power plants. Since the magnitude of DG indicated in PlaNYC was of similar magnitude, the non-base load eGrid greenhouse gas emissions coefficients were used to estimate the potential impacts of the distributed CHP systems in New York City.

The emissions reductions for the potential CHP systems were determined using the following equation:

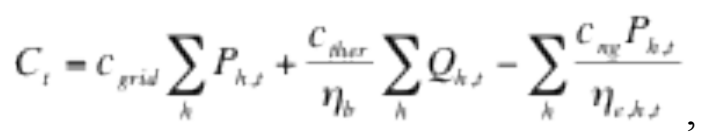

where $C_{t}$ is annual $\mathrm{CO}_{2}$ e emissions reductions for building or microgrid, $\mathrm{t}, c_{\text {grid }}$ is the non base load New York City/Westchester $\mathrm{CO}_{2} \mathrm{e}$ emission coefficient as reported by the 2012 eGrid assessment $\left(\mathrm{CO}_{2} \mathrm{e} / \mathrm{kWh}_{\mathrm{e}}, 2009\right), \eta_{\mathrm{b}}$ is the assumed boiler efficiency of $85 \%, c_{\text {ther }}$ is the average $\mathrm{CO}_{2} \mathrm{e}$ coefficient for non electricity building energy use (steam, fuel oil, and natural gas), $\eta_{\mathrm{eh}, \mathrm{t}}$ is the electrical efficiency of the proposed CHP unit in hour, h, for building or microgrid, $\mathrm{t}$, and $c_{n g}$ is the $\mathrm{CO}_{2} \mathrm{e}$ coefficient for natural gas, the CHP fuel source. All $\mathrm{CO}_{2} \mathrm{e}$ emissions coefficients were from the year 2009.

\subsection{CHP Potential at the Building and Microgrid Scales}

With the viability criteria established (thermal and electrical load, minimum size requirement, and minimum efficiency requirement), the potential capacity and emissions reductions were estimated for each tax lot and microgrid in New York City. At the building level, the electric load following methodology previously discussed identified 2,348 potential CHP systems with an aggregate electrical capacity of 1,579 MW. Each system on average would reduce emissions of $\mathrm{CO}_{2} \mathrm{e}$ by $17 \%$ when compared to separate electricity and thermal energy generation. At the microgrid level, the electric load following strategy identified 4,714 systems with an aggregate capacity of 3,042 MW. Each system on average would reduce emissions of $\mathrm{CO}_{2} \mathrm{e}$ by $16 \%$ when compared to separate electricity and thermal generation. Also, each building and microgrid system would have net positive emissions reductions using average emissions coefficients of the current mix of fuels and technologies used to produce electricity and thermal energy. If every potential system were installed, it would lead to $4 \%$ and $9 \%$ aggregate citywide emissions reductions at the building and microgrid scales, respectively. A sideby-side comparison of the number of systems, aggregate capacity, average site $\mathrm{CO}_{2} \mathrm{e}$ emissions reductions, and aggregate $\mathrm{CO}_{2} \mathrm{e}$ emissions reductions for each scenario is shown in Table 5. 
Table 5. Number of CHP systems, potential CHP electrical capacity, and average percent site emissions reductions (compared to grid provided electricity and on site boiler) for building and microgrid systems.

\begin{tabular}{|c|c|c|c|c|}
\hline & $\begin{array}{c}\text { Number of } \\
\text { Systems }\end{array}$ & $\begin{array}{c}\text { Aggregate } \\
\text { Electrical } \\
\text { Capacity } \\
\text { (MW) }\end{array}$ & $\begin{array}{c}\text { Average Site } \\
\mathrm{CO}_{2} \mathrm{e} \\
\text { Emissions } \\
\text { Reduction }\end{array}$ & $\begin{array}{c}\text { Aggregate } \\
\mathrm{CO}_{2} \mathrm{e} \\
\text { Emissions } \\
\text { Reductions, } \mathrm{M} \\
\text { Metric tons }\end{array}$ \\
\hline Building Level & 2,348 & 1,579 & $17 \%$ & 2.3 \\
\hline $\begin{array}{c}\text { Microgrid } \\
\text { Level }\end{array}$ & 4,714 & 3,042 & $16 \%$ & 5.0 \\
\hline
\end{tabular}

The CHP system capacities vary widely at both the building and microgrid scale from $30 \mathrm{~kW}$ to greater than $5 \mathrm{MW}$. The distribution of the system capacities as well as the aggregate capacity within each size range is shown in Figure 2. The distribution of system size is fairly similar between the building and microgrid scenarios, although the magnitude of the potential microgrid systems is larger in number and aggregate capacity. The majority of systems in each case fall within the $100-250 \mathrm{~kW}$ capacity range, although the largest capacity is within the 1,000$2,500 \mathrm{~kW}$ range. This indicates that there are opportunities for distributed CHP development at the $\mathrm{kW}$ and MW scales for both buildings and microgrids.

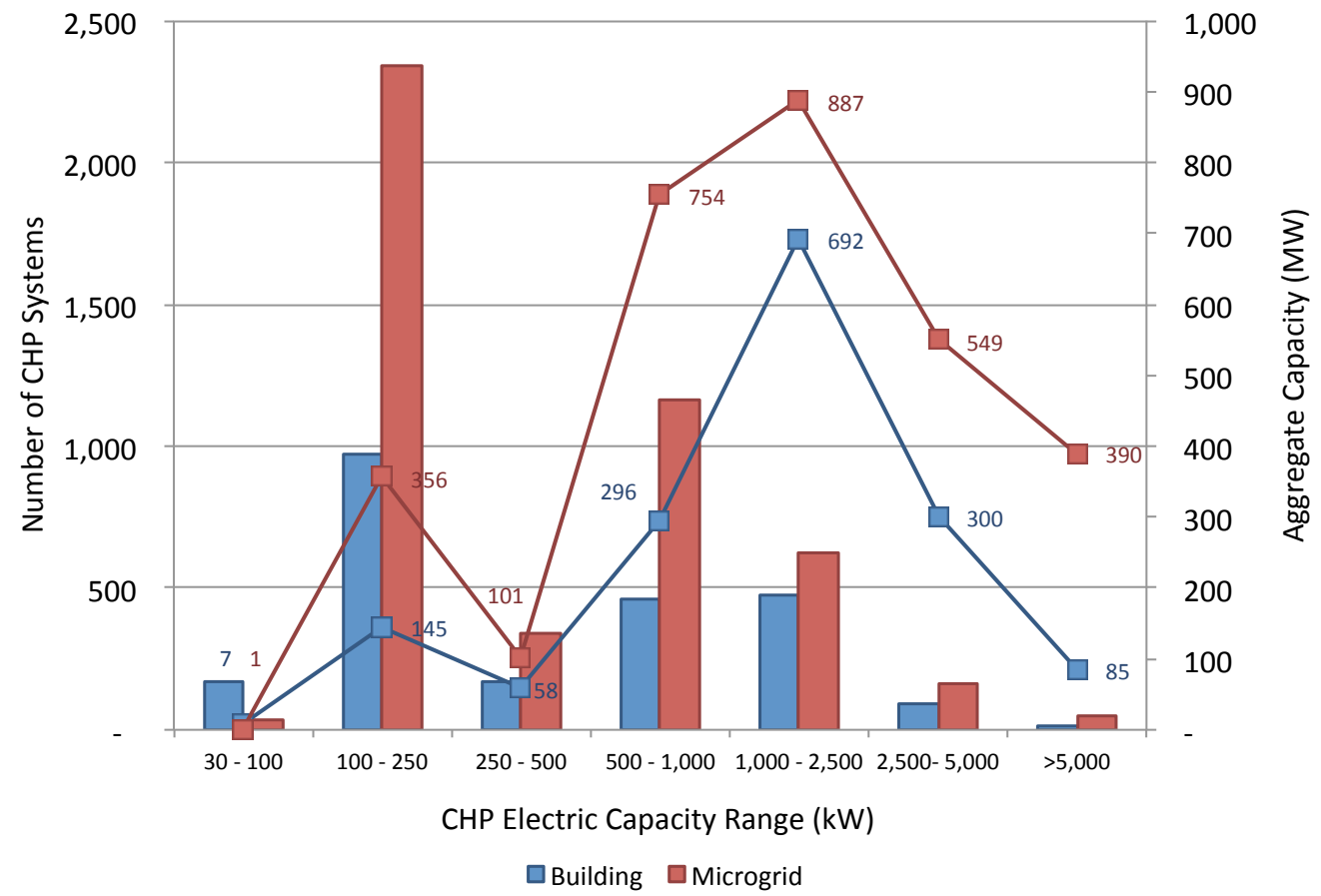

Figure 2. Number of CHP systems within a certain capacity range for the building- and microgrid-level CHP opportunities. Aggregate capacity shown for each range in MW.

The complexity of the ownership structure for a CHP system varies by the type of customer served. Figure 3 depicts the percentage of building floor area served 
by type for both the building and microgrid level systems. While the smallest systems $(30-100 \mathrm{~kW})$ are utilized for mostly other commercial building types, the remaining systems serve primarily residential and office buildings. For both building and microgrid CHP systems, office buildings become a significant proportion of the building types served after $1 \mathrm{MW}$, due to their large amount of electricity consumption in relation to the thermal demands as well as larger CHP systems producing more electricity than thermal energy. Multi-family buildings energy demands would be served for both building and microgrid CHP systems greater than $100 \mathrm{~kW}$. 1-4 family residential buildings are prevalent in microgrid systems less than $250 \mathrm{~kW}$.

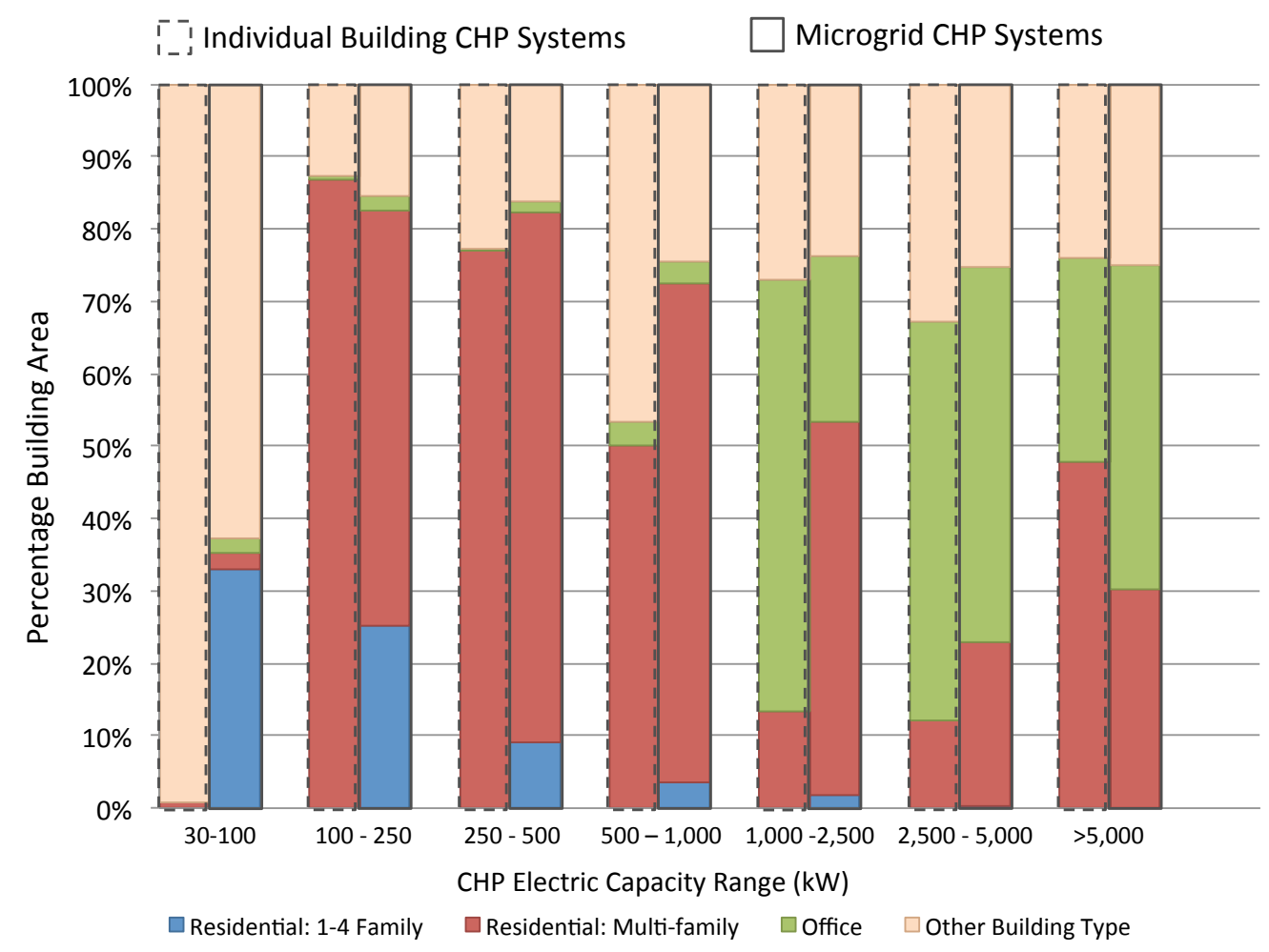

Figure 3. Percentage of building floor area served by building type and system size for estimated building and microgrid CHP systems. (100\% includes all building area served by either building or microgrid CHP systems with electric capacities within the specified range)

For the current analysis, a "microgrid system" considered every building on a block and estimated the size and system capacity ensuring a minimum $60 \%$ annual efficiency. As different building types have different electrical and thermal demand profiles, the aggregation of some or all building types at various magnitudes may not be beneficial. Since the current analysis did not sub-select for optimal building aggregation, it was important to view the difference in efficiencies between the identified building level systems and the microgrid systems located on the same block. The metric of comparison was the annual CHP efficiency for the microgrid system minus the average annual efficiency of the building level CHP systems identified on the block. 
Figure 4 shows a map of the annual efficiency differences, as well as a chart of their distribution. First to note, there were many blocks for which no building level CHP systems were identified as feasible, though a microgrid was identified as feasible. The analysis indicates that $3,128(66 \%)$ of the microgrid systems with an aggregate capacity of $996 \mathrm{MW}$ (33\% of identified microgrid capacity) fit that scenario. This means that none of the individual buildings had a large enough estimated electric and thermal demand to require a system of at least 30 $\mathrm{kW}$ or would not have operated at $60 \%$ annual efficiency, but all buildings on the block aggregated and served by a single microgrid were feasible. For the remaining systems, 466 (10\%) microgrid systems with $772 \mathrm{MW}(25 \%)$ aggregate capacity would operate at efficiencies 1 to $10 \%$ higher than the average building level systems. 948 (20\%) microgrid systems with 1,167 MW (38\%) aggregate capacity were within $\pm 1 \%$ of the average building level systems. In contrast, 172 (4\%) microgrid systems with an aggregate capacity of $107 \mathrm{MW}(4 \%)$ would operate at 1 to $9 \%$ less efficient than the average building level systems identified on the block. In these scenarios, an individual building has thermal and electric profile that can be met efficiently with a certain size CHP system. The addition of different buildings with different profiles while also utilizing larger systems reduces the annual efficiency but is still able to operate with greater than $60 \%$ annual efficiency. While these systems operate less efficiently on average than their building level counterparts, each microgrid system reduces greenhouse gas emissions when compared to completely separate electric and thermal services. 


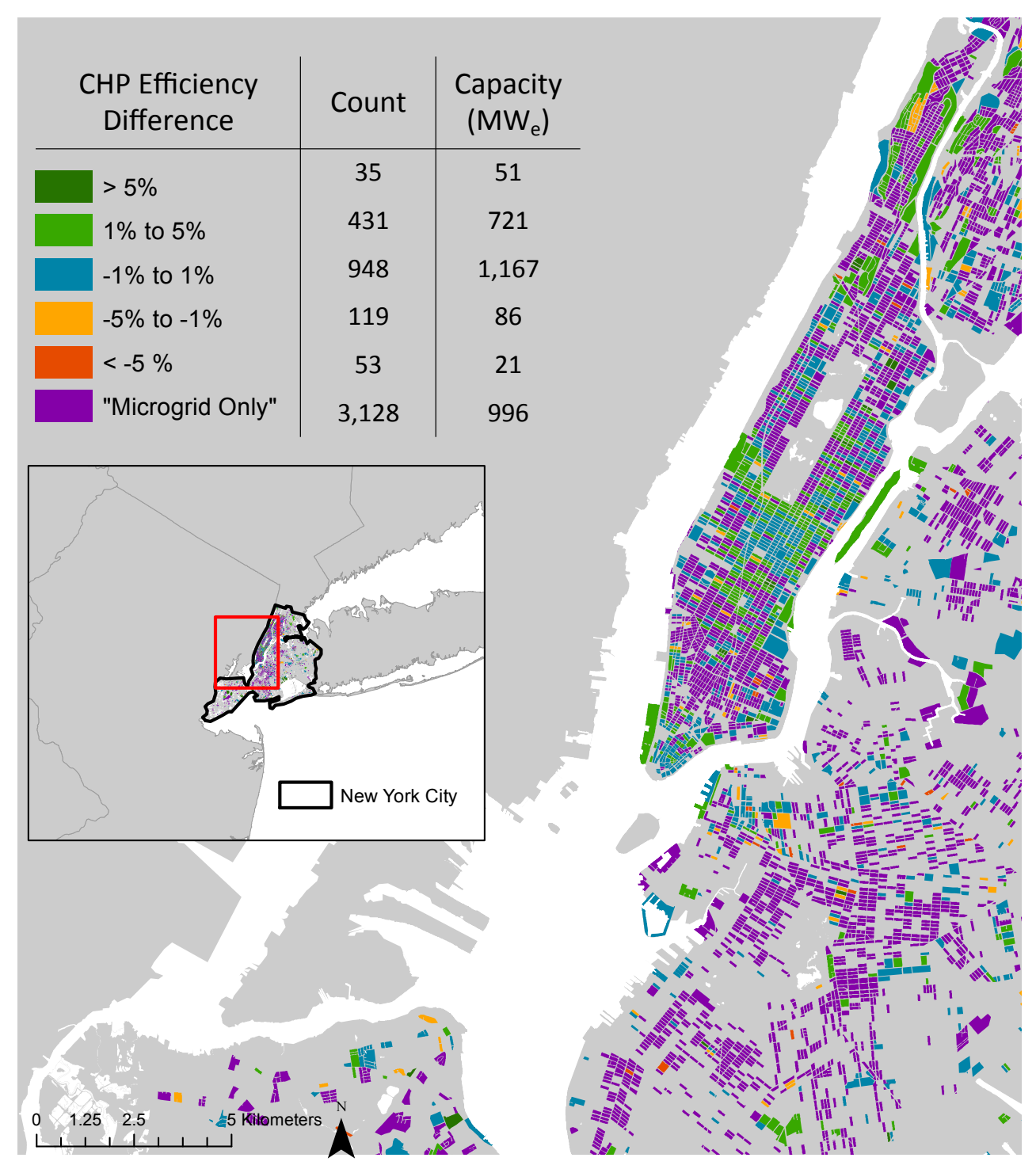

Figure 4. Comparison of annual and average CHP efficiencies of identified building and microgrid systems located on the same block (+ indicates microgrid annual CHP efficiency is larger, - indicates the average building CHP efficiency

is larger). "Microgrid only" signifies no building level CHP systems were identified as feasible on the same block.

However, the development of CHP systems requires more than just available demand, it also requires consideration of the implementation process and the associated costs. Sections 2, 3, and 4 discussed the many aspects that make CHP difficult to implement as well as some measures that have been implemented to ease the development of CHP. The next section will discuss the identified measures to facilitate CHP in New York City and will evaluate whether or not the estimated systems would be able to take advantage of those measures.

\section{Assessment of CHP to meet Sustainability Goals}

This section assesses the applicability (qualifications based on capacity and efficiency) of financial incentives, standard interconnection requirements, and air 
permitting requirements in relationship to the estimates of CHP system sizes throughout New York City at both the building and microgrid scales.

\subsection{Financial Incentives}

A common eligibility requirement of the now discontinued NYSERDA financial incentives previously discussed is a minimum annual efficiency of $60 \%$. The previous engineering analysis used this threshold as viability criteria, which indicates that the $800 \mathrm{MW}$ of distributed generation as laid out by New York City's sustainability plan could be achieved while maintaining acceptable efficiencies at both the building and microgrid levels. Assuming that the same efficiency requirements of NYSERDA's previous programs will be utilized in future initiatives for modular CHP kits up to $1.3 \mathrm{MW}$, the analysis indicated that 340 building level systems aggregating to $811 \mathrm{MW}$ and 510 microgrid systems aggregating to $1,463 \mathrm{MW}$ would be eligible to receive incentives from this program.

\subsection{Applicability of Streamlined Interconnection Standards}

The number of systems for each engineering viability scenario that would be allowed to follow the SIR is shown in Table 6. At both the building and microgrid levels, the majority of systems are less than 2 MW, 93\% and 94\% respectively, meaning these systems would be qualified to use the SIR.

Table 6. Number of CHP systems that qualify for use of standard interconnection requirements versus total number of potential systems.

\begin{tabular}{|c|c|c|}
\hline & Number of CHP Systems & Aggregate Capacity (MW) \\
\hline Building Level & 2,175 & 1,037 \\
\hline $\begin{array}{c}\text { Microgrid } \\
\text { Level }\end{array}$ & 4,423 & 1,920 \\
\hline
\end{tabular}

CHP systems larger than $20 \mathrm{MW}$ are covered by the New York Independent Systems Operator (NYISO) Standard Large Facility Interconnection Procedures (LFIP), which allow for streamlined development similar to the SIR. In between these two size capacities (2MW and 20MW), systems would require case-bycase interconnection analysis by the utility. From the estimates, 542 to 1,122 MW of potential CHP capacity at the building and microgrid levels respectively would not be covered by any standard interconnection procedures and therefore would likely undergo a longer interconnection process than those systems covered by these procedures.

\subsection{Potential Impacts of Air Permitting}

To determine the impacts of permitting on the potential CHP systems, an estimate of the types of permits that would need to be obtained was performed. The estimates were made utilizing the capacity ranges outlined by Bourgeois et al., 2010. The number and capacity of CHP systems required to register or obtain permits at both the building and microgrid levels are shown in Table 7. For each 
scenario, the majority of CHP systems identified would be exempt or only require minor facility registration. However, the majority of the capacity would be required to obtain a State or Major Facility permit. The systems requiring a permit (versus registration) would likely take longer to develop or be avoided because of the time entailed in the permitting process and because this issuance of a permit triggers more detailed reviews, which also adds time and possibly cost to the development process.

Table 7. Capacity (Number) of potential CHP systems falling within the different air permitting levels.

\begin{tabular}{|c|c|c|c|c|}
\hline & $\begin{array}{c}\text { Exempt/ } \\
\text { Trivial } \\
\text { Source } \\
\text { MW (\#) }\end{array}$ & $\begin{array}{c}\text { Minor } \\
\text { Facility } \\
\text { Registration } \\
\text { MW (\#) }\end{array}$ & $\begin{array}{c}\text { State } \\
\text { Facility } \\
\text { Permit } \\
\text { MW (\#) }\end{array}$ & $\begin{array}{c}\text { Major } \\
\text { Facility Title } \\
\text { V permit } \\
\text { MW (\#) }\end{array}$ \\
\hline $\begin{array}{c}\text { Building } \\
\text { Level }\end{array}$ & $94(847)$ & $266(742)$ & $408(419)$ & $811(340)$ \\
\hline $\begin{array}{c}\text { Microgrid } \\
\text { Level }\end{array}$ & $203(1,614)$ & $638(1,786)$ & $738(804)$ & $1,459(509)$ \\
\hline
\end{tabular}

\section{Conclusions and Policy Implications}

Based on the estimated energy demands, there is significant potential for combined heat and power systems at both the building and microgrid scales at $\mathrm{kW}$ and MW capacities. Building level systems, if each implemented, would aggregate to 1,579 $\mathrm{MW}_{\mathrm{e}}$ and microgrid systems would aggregate to 3,042 $\mathrm{MW}_{\mathrm{e}}$ with each system operating at a minimum $60 \%$ annual CHP efficiency. While the $16 \% \mathrm{CO}_{2} \mathrm{e}$ reductions, with respect to separate electric and thermal production, can be met for individual systems, if each system were implemented the overall emissions reductions would be 2.3 million metric tons and 5.0 million metric tons at the building and microgrid scales respectively. In comparison to the total $\mathrm{CO}_{2} \mathrm{e}$ emissions from the city in 2009 , this would be a reduction of $4 \%$ or $9 \%$ in greenhouse gas emissions at the building and microgrids scales respectively.

In contrast, due to physical, regulatory, and economics constraints, each of the systems would most likely not be installed, suggesting the emission benefits from each system would not be realized. These estimates provide an upper bound on the amount of emission savings expected from these systems across the city and only accounts for the current fuel mix utilized to supply electricity to the grid. As the grid incorporates more renewable energy sources, these emissions benefits will diminish.

However, combined heat and power provides other benefits besides emission reductions, such as reduction of load during peak electrical demand periods, which adds reliability to the electric grid. With concerns of resiliency, combined heat and power in the form of distributed generation could have additional 
impacts. Both the potential emission reductions and the added reliability should be factors in evaluating the value of CHP systems.

When considering the measures implemented to help facilitate CHP, at least 800MW of potential CHP systems would qualify for standard interconnection requirements as well as previous and future financial incentives. On the other hand, less than $800 \mathrm{MW}$ of building level CHP systems would be classified as a trivial source or just require minor registration for air permitting. To achieve the DG goal outlined by the City utilizing only building scale systems would require the installation of systems that require state facility or major facility air permits. These permits, while relatively timely to obtain, also trigger other requirements that must be implemented by CHP developers. However, there are many smaller systems at the microgrid scale that would only require minor registration. After considering the regulatory constraints and more specifically air permitting requirements, the potential for CHP systems at the building level dwindles to 360 MWe and at the microgrid level to $841 \mathrm{MWe}$.

Microgrid systems, as indicated by the analysis, could have multiple impacts by operating more efficiently while providing energy to buildings that would not be able to utilize CHP on their own due to their size or load profiles. But as outlined by Hyams (2010) and Gerrard (2013), there are still many hurdles to microgrid development within the current regulatory framework, especially if microgrids incorporate residential customers, which the current analysis indicates may be prevalent. The definition of microgrids, as well as regulations imposed depending on the ownership structure, is still ambiguous. To achieve the desired amount of CHP as outlined in PlaNYC, it may become necessary to develop a more defined framework for the implementation of microgrids supplied by CHP in New York City.

Overall, the analysis outlined by this paper provides a framework for assessing the potential for CHP at building and block scales while being inclusive of the incentives and regulatory standards that emphasize CHP. Incentives for CHP systems may have been developed piecemeal over time and revisiting them to develop one clear package can provide guidance on which new policies are needed to facilitate CHP. While in this analysis air permitting was the limiting factor, for other municipalities it may be a flexible policy that reduces the ease of CHP deployment. Through the methodology described in this paper, one could assess how that policy could or should be changed to achieve the desired objectives. 


\section{References}

ASHRAE, 2008. 2008 ASHRAE Handbook, Heating, ventilating, and air conditioning systems and equipment, Chapter 7: Combined Heat and Power Systems, American Society of Heating, Refrigerating and Air-Conditioning Engineers, Inc.

Bourgeois, T., Hedman, B., Zalcman, F., 2003. Creating markets for combined heat and power and clean distributed generation in New York State, Environmental Pollution, 123, 451-462

Bourgeois, T., Hedman, B., Hinge, A., Joshi, A., May 2003, Clean distributed generation in New York State: State and Local Siting, Permitting, and Code Issues, NYSERDA, http://energy.pace.edu/sites/default/files/publications/Pace_CHP_Siting_Guidebook.pdf

Casisi, M., Pinamonit, P., Reini, M., 2009. Optimal lay-out and operation of combined heat and power (CHP) distributed generation systems, Energy, 34, 2175-2185

CCAP, 2001. Promoting Clean Power, Clean Air and Brownfield Redevelopment, US EPA, http://www.siame.gov.co/siame/documentos/documentacion/mdl/03 VF Bibliografia/Industria/E lectric\%20power\%20industry.pdf

Chittum, A., Kaufman, N., 2011. Challenges Facing Combined Heat and Power Today: A Stateby-State Assessment, American Council for an Energy-Efficient Economy, http://aceee.org/research-report/ie111

Crawley, D., Lawrie, L., Winkelmann, F., Buhl, W., Huang, J.Y. , Pedersen,C., et al., EnergyPlus: creating a new-generation building energy simulation program, 2001. Energy Build, 33, p.243

Finney, K., Sharifi, V., Swithenbank, J., Nolan, A., White, S., Ogden, S., 2012, Developments to an existing city-wide district energy network - Part I: Identification of potential expansions using heat mapping, Energy Conservation and Management, 62, 165-175

GE Energy, 2011. Jenbahcer Type 2 Technical Specifications. 2011,http://www.geenergy.com/products_and_services/products/gas_engines_power_generation/ge_jenbacher_type_ 2_gas_engine.jsp

Gerrard, M., Reducing Legal Hurdles to Combined Heat and Power in New York, May 8 2013, New York Law Journal, http://www.newyorklawjournal.com/PubArticleNY.jsp?id=1202599056118\&Reducing_Legal_H urdles_to_Combined_Heat_and_Power_in_New_York\&slreturn=20130413142647

Hammer, S., Mitchell, J., 2007, CHP in NYC: A Viability Assessment, http://www.stephenhammerphd.com/uploads/1/0/4/1/10415201/chp_study_2007.pdf

Hawkes, A.D., Leach, M.A., Cost-effective operating strategy for residential micro-combined heat and power, Energy, Volume 32, Issue 5, May 2007, Pages 711-723

Howard, B., Parshall, L., Thompson, J., Hammer, S., Dickinson, J., Modi, V., 2012. Spatial distribution of urban building energy consumption by end use, Energy and Buildings, 45, pp. $141-151$

Hyams, M., 2010, Microgrids: An assessment of the value, opportunities and barriers to development in New York State, NYSERDA, Report 10-35, http://www.nyserda.ny.gov/Publications/Research-and-Development-Technical-Reports/ElectricPower-Delivery-Reports.aspx

Keirstead, J., Samsatli, N., Shah, N., Weber, C., 2011. The impact of CHP (combined heat and power) planning restrictions on the efficiency of urban energy systems, Energy, 41, 93-103 
Lemar, P., 2001. The potential impact of policies to promote combined heat and power in US industry, Energy Policy, 29, 1243-1254

Mueller, S., 2006. Missing the spark: An investigation into the low adoption paradox of combined heat and power technologies. Energy Policy, 34, 3153-3164

New York State Public Service Commission (NYS PSC), 2012. Distributed Generation Information,

http://www3.dps.ny.gov/W/PSCWeb.nsf/All/DCF68EFCA391AD6085257687006F396B?OpenD ocument.

NYC, 2007. PlaNYC: A Greener Greater New York, http://www.nyc.gov/html/planyc2030/html/publications/publications.shtml

NYSERDA, 2012a. Existing Facilities Program, http://www.nyserda.ny.gov/Commercial-andIndustrial/CI-Programs/Existing-Facilities-Program.aspx

NYSERDA, 2012b. CHP Acceleration Program, http:/www.nyserda.ny.gov/FundingOpportunities/Current-Funding-Opportunities/RFI-2568-CHP-Acceleration-Program-CHPSystem-Prequalification.aspx

Peters, J., DeSimoine, T., 2011, Process Evaluation: Distributed Generation and Combined Heat and Power Demonstration, NYSERDA, Project Number 9835,

Ren, H., Zhou, W. Nakagami, K. Gao, W., Wu, Q., 2010. Feasibility assessment of introducing distributed energy resources in urban areas of China, Applied Thermal Engineering, 30, 25842593

U.S. Department of Energy (US DOE). 2011. Commercial Building Initiative: Commercial Reference Buildings,

http://www1.eere.energy.gov/buildings/ commercialinitiative/ reference buildings.html

U.S. EPA, 2008. Combined Heat and Power Partnership, Catalog of CHP Technologies, http://www.epa.gov/chp/technologies.html

US EPA, 2012. eGRID2012, Emissions \& Generation Resource Integrated Database, Version 1.0, http://www.epa.gov/cleanenergy/energy-resources/egrid/index.html

Wang, J., Jing, Y., Zhang, C., Zhai, Z., 2011. Performance comparison of combined cooling heat and power system in different operation modes, Applied Energy, 88, 4621-4631 